\title{
GLOSAS A UN TRABAJO DE INVESTIGACION HISTORICO-PEDAGOGICA
}

\section{Cesar A. Vera Gil}

El tomo dos del trabajo de Alberto Echeverry sobre el proceso de constitución de la instrucción pública 1819-1835, cuya primera parte fue publicada en 1985, constituye un valioso aporte a la escasa bibliografía que sobre la Historia de la Educación y la Pedagogía existe actualmente.

En reciente seminario sobre Investigación en Educación y sobre la temática específica del devenir Histórico de la educación señalábamos que "viene caracterizándose por una gran falta de continuidad. En particular, la investigación universitaria nacional viene operando como si cada palabra que tratara de afirmar fuera siempre la primera"99. Pero en el caso del trabajo del profesor de la Universidad de Antioquia, se percibe una vertebración de su producción investigativa, cuyo hilo conductor ha sido el proyecto interuniversitario de la Historia de la Práctica Pedagógica, el cual ha generado numerosos productos que han contribuido al análisis y conservación de nuestro patrimonio cultural.

Ahora bien, si es cierto que su enfoque metodológico está enmarcado dentro de las directrices del proyecto global, los acentos particulares en el manejo de la palabra escrita y la admiración del autor por escritores como Carrasquilla y Fernando González, dan a su prosa un carácter literario y algo anti-académico. De otro lado, el cuerpo del trabajo evidencia un riguroso manejo documental y una profundaidad de análisis de la cual adolecen los pocos escritos que sobre este objeto se pueden consultar. Si tenemos en cuenta la corta duración del período estudiado (16 años de historia Republicana), podemos darnos cuenta que, la histografía colombiana comienza a superar la etapa en la cual para que una investigación fuera considerada algo relevante, debía abordar por lo menos medio siglo de Historia.

Especial interés merece en el documento el capítulo correspondiente a la gran polémica ideológica que se dio en torno a la enseñanza del pensamiento de Bentham y Tracy. Se explica cómo las distintas fuerzas sociales tuvieron como escenario a la escuela (no en el sentido estrecho del término) en una disputa donde jugaron papel fundamental la Iglesia, los balbuceantes partidos políticos, la prensa, el aparato militar, etc.

Se analiza allí, de que manera, la Iglesia como máxima exponente del "poder moral", en su afán por reconquistar su magisterio perdido a raíz del plan de 1826, modifica ágilmente sus mecanismos y objetos de control social. Si bien es cierto que en 1835 los partidarios de los autores europeos, intentan recuperar el espacio perdido "el plan Santander y la enseñanza de Bentham no volverán a ser los que fueron durante la administración del vicepresidente Santander" (p. 259).

Finalmente, "el poder moral derrota a Bentham", como ha derrotado tradicionalmente el pensamiento que aspire a modificar en algo el control sobre el manejo del cuerpo y de la conciencia. Señala entonces Echeverry "terminada la labor de los ejércitos y la mano dura con los vencidos recetada por Caro, era apenas lógico que sobre los sobrevivientes se derramase. la sabiduría jesuítica" (p. 367).

\footnotetext{
* Sociólogo M.S. Psicólogo (c) Ph.D. Profesor de la Facultad de Artes y Humanidades. Universidad Pedagógica Nacional.

${ }^{99}$ SILVA, Renán. Relatoría mesa 4 del Tercer Seminario Nacional de Investigación en Educación. ICFES, Bogotá, 1986.
} 
Con la lectura de esta investigación vemos que el gran eje de análisis que subyace en ella, es el de las múltiples relaciones entre la educación como tecnología de poder y las restantes fuerzas sociales. No quiere con ello decirse que se trata de un trabajo de corte "sociologista" en la acepción que se le da actualmente a este término, pues su orientación hacia el enfoque de la "Arqueología del Saber" es demasiado evidente.

La importancia de este estudio no debe ser entendida simplemente dentro de los cánones de una producción académica que merece un reconocimiento "científico", sino como un aporte de un juicioso investigador que ha estado vinculado muy cercanamente a El Movimiento Pedagógico y a la recuperación de la palabra de y para el maestro.

Si bien es cierto que el escrito aborda la época de los albores de nuestra Historia Republicana, contribuye al estudio y explicación de las prácticas pedagógicas actuales, del carácter de intelectuales subalternos de los maestros colombianos y del accidentado proceso de relaciones entre la Iglesia y el Estado.

En síntesis, las características metodológicas, el manejo de la prosa y de la masa documental del trabajo de Echeverry, lo constituyen en un interesante y polémico producto de investigación histórico-pedagógica. 